\title{
Proposals for Zhejiang to Accelerate the Layout of Overseas Innovation Centers in the Context of the Belt and Road Initiative
}

\author{
Lingling Zuo \\ Ningbo University of Finance and Economics, Ningbo, China
}

Keywords: Zhejiang; Belt and road initiative; Overseas innovation center; Suggestions

\begin{abstract}
In September 2016, the Ministry of Science and Technology and other ministries and commissions jointly issued the "Special Plan for Promoting the "Belt and Road" Construction of Scientific and Technological Innovation Cooperation”, and proposed that all localities should actively carry out scientific and technological innovation cooperation with distinctive characteristics and priorities in accordance with local conditions. Promote the construction of international science and technology innovation cooperation platforms such as science and technology parks. In May 2017, when Xi Jinping attended the "Belt and Road" international cooperation summit forum, he announced the launch of the "Belt and Road" science and technology innovation action plan and made the cooperation in science and technology parks one of the four actions. In April 2019, the second "Belt and Road" International Cooperation Summit Forum, China signed cooperation documents with the Ministry of Science and Technology of Austria, Japan, Mexico, Israel, Greece, Uzbekistan, South Africa, Israel, Malta, Indonesia and other countries. The positive response from countries along the "Belt and Road" has become a hot spot for international scientific and technological innovation cooperation between China and countries along the Belt and Road. This article first proposes the establishment of overseas innovation centers as a new strategy to participate in international competition. Secondly, it introduces the experience of overseas innovation centers at home and abroad, and finally gives suggestions for accelerating the layout of Zhejiang's overseas innovation centers in the context of the Belt and Road Initiative.
\end{abstract}

\section{Establishing Overseas Innovation Centers is a New Strategy to Participate in International Trade Competition.}

\subsection{Master the latest developments in international scientific and technological innovation}

At present, the development of international scientific and technological cooperation has consisted of the first-generation science and technology industrial parks that accelerate the transfer of scientific and technological achievements, and the second-generation science and technology parks that have undergone overall planning, highlight innovation and incubation, and emphasize the close integration of science and technology. Developed into a third-generation science and technology park (also called offshore innovation center) based on the concept of knowledge ecology, led by talents, centered on creativity, and emphasized the integration of communities and cities [1]. The establishment of an offshore innovation center can stabilize China's economic strength by introducing advanced foreign technologies and innovations, and make it more competitive in national trade. So far, some areas in China have achieved good results with the help of the Offshore West Innovation Center. However, in the past 5 years in Zhejiang Province, domestic science and technology cooperation has been mainly carried out, and the use of science and technology resources of colleges and institutes to serve enterprise innovation has achieved remarkable results. However, compared with domestic scientific and technological cooperation, Zhejiang still lacks in the establishment of offshore innovation centers. Although it has also participated in a series of international scientific and technological cooperation in the United States, Ukraine, Russia, Israel and other countries, it is far from solving the problem and supporting enterprise R \& D. "Going out" still has a long way to go. 


\subsection{Track the latest technology development in the world}

With the support and platform of science and technology industrial parks, it is effective in promoting the transfer of applicable technologies and the transformation of achievements, and building long-term and stable cooperative relationships, thereby enhancing the technological capabilities of countries along the Belt and Road. Through the establishment of science and technology characteristic parks with the countries along the route, it can guide and encourage our province's high-tech zones, independent innovation demonstration zones, marine science and technology industrial parks, environmental protection industrial parks, etc. to actively connect with the countries along the route, and track the latest technology development in the world. The manufacturing industry provided favorable support for the transformation of high-tech industries, and also provided a guarantee for the transformation of China's economy. Therefore, grasping the latest developments in international scientific and technological innovation is not only an important means for enterprises to improve their technological innovation capabilities, but also to improve their international competitiveness.

\subsection{Gathering the best talents for global scientific and technological progress}

The third-generation science and technology park emphasizes taking people as the core and inspiring people's creativity as the characteristics [2]. It is a knowledge-based community that integrates learning, work, and entertainment in the context of a knowledge economy. Unlike the first-generation science and technology parks, which emphasize linear innovation and the second-generation science and technology parks, which emphasize chain innovation, the third-generation science and technology park is led by the gathering of talents, with the basic mission of stimulating creativity, and based on network interactive innovation. All kinds of talents, enterprises, networks and knowledge, and create effective knowledge ecology for effective cooperation. Therefore, the establishment of overseas science and technology parks can gather the best talents for scientific and technological progress in the world for Zhejiang.

\section{Lessons from the Construction of Overseas and Domestic Innovation Centers}

\subsection{Give play to the incubation role of overseas $R \& D$ institutions}

R \& D offshore control mode. This mode mainly refers to the establishment of wholly-owned or joint-venture R \& D centers in countries other than the country, which has achieved the purpose of $\mathrm{R} \& \mathrm{D}$. This model is generally established in developed countries, and it is preferred to the United States and Britain. From the mature overseas science and technology park development experience at home and abroad, all countries in the world attach importance to the role of R \& D institutions in incubation and demonstration. In the United Kingdom, it has become quite popular for academic research institutions to establish institutions related to entrepreneurship and incubation. Most incubators exist in the form of science parks. Universities provide venues, houses and equipment and gradually develop into clusters of innovative industries with universities as the core. For example, Wuhan East Lake High-tech Zone has set up Optics Valley Offshore Innovation Center and Overseas Technology Park in Silicon Valley in the United States, the United Kingdom, Thailand and other places; Xi'an High-tech Zone has also established offshore innovation centers in more than 10 incubators in Silicon Valley, and continues to Establish R \& D centers in countries related to the Belt and Road Initiative [3].

\subsection{Improve overseas technology innovation system}

The core of overseas innovation centers is the innovation of science and technology, so building a perfect technological innovation system is the key to the sustainable development of high-tech parks. After the implementation of measures such as the introduction of enterprises, scientific research institutions, and high-end talents to achieve the aggregation of factors such as innovation, we should focus on the development of innovation clusters, deepen the connection between the main elements of each element, and form a long-term stable innovation network system by 
constructing regional industrial networks and social networks. Through the positive interaction of various innovation elements, the independent innovation capability of enterprises in China's science and technology parks will be improved, and the function of incubating high-tech enterprises in the park will be brought into full play. For example, the Shanghai Jiaotong University Research Institute, as an industry-university-research cooperation institution registered in Zhangjiang Science and Technology Park, relies on its experience and advantages in international cooperation to register and establish the Siberian nanomaterials offshore industry innovation in Russia.

\subsection{Constructing overseas intermediary service networks}

The rapid development of the Silicon Valley in the United States shows that it is more conducive to technological innovation is its developed intermediary organization, because from the birth of ideas to the production of products, the wisdom and efforts of numerous intermediary service organizations have been consolidated [4]. Many times, due to the influence of their own strength and financial resources, they can choose to cooperate with the intermediary to leverage their mature technological achievements to achieve the process of quantitative change to qualitative change. At the same time, the professionalism and efficiency of the intermediary service system allows technology companies to have more time and energy to consider core issues in technological innovation and production operations, and to enjoy the results of technology spillovers from other technology companies for free.

\subsection{Establishing overseas risk prevention and control mechanisms}

Investment enterprises in China are facing investment and financing decision-making, management, and service risk challenges. In order to effectively prevent and reduce investment risks, they should make overseas investments on the basis of implementing a "localized" business development strategy and implement a "win-win" strategy. The practice of European and American countries shows that venture capital investment should be the main driving force for the transformation of scientific and technological achievements into production, and it should be the lifeline for the steady development of science and technology parks. Take Silicon Valley in the United States as an example. Silicon Valley's venture capital structure is relatively reasonable. Private companies account for $40 \%$ of the investment, and various financial institutions and small investments each account for $30 \%$. The investment objects are mainly small and medium-sized high-tech enterprises, of which 3/4 of the venture capital is concentrated in the high-tech field. It can be said that there is a symbiotic relationship of "one loss and one loss, one glory and one glory" between high-tech companies in Silicon Valley and venture capital.

\subsection{Pay attention to government guidance for overseas investment}

The government's support is based on the most practical actions and the most favorable policies for the successful development of the park. In order to further encourage entrepreneurship and innovation so that Chinese innovative enterprises can develop better, the government can implement preferential policies for technology business incubators, university science parks, and Zhongchuang Space. At the same time, the government must do a good job of supervision and correct problems in a timely manner to ensure the healthy development of the science and technology park, improve the economic benefits and sustainable development of the park, and give full play to the market mechanism while fully positioning the government's functions. . At present, 11 free trade zones across the country have issued policy support for offshore innovation and entrepreneurship.

\section{Proposals for Zhejiang to Layout Overseas Innovation Centers in the Context of the Belt and Road Initiative}

\subsection{Layout overseas innovation centers based on overseas economic and trade cooperation} zones

Strengthen overseas trade cooperation and lead demand with emerging trade. Zhejiang's 
Internet-based retail business has always been an important force for expanding domestic demand. Zhejiang's retail business accounts for $1 / 5$ of the country. By the end of 2018, Zhejiang Province had 12 provincial and overseas economic and trade cooperation zones in countries along the "Belt and Road". Therefore, under the coverage of the "Belt and Road" transportation network, Zhejiang Province should accelerate the formation of an industrial layout of international regional division of labor and cooperation, and realize the internal and external linkage between the cooperation zone and the local, the cooperation zone and the home country, and the cooperation zone and the third party zone Bringing domestic advantages out, speeding up the construction of overseas economic and trade cooperation zones, taking advantage of Zhejiang's existing overseas economic and trade cooperation zones, and promoting its transformation and upgrade from an "industrial zone" to a "sci-tech innovation zone" [5].

\subsection{Focusing on the layout of overseas innovation centers along the international train lines}

Under the gradual formation of the "Belt and Road" transportation network, Zhejiang should expand the scope and scale of industrial cooperation with countries along the route, accelerate the formation of an industrial layout of international regional division of labor and cooperation, and achieve cooperation between the cooperation zone and the local area, cooperation zone and the home country, Cooperation between the cooperation zone and the third-party zone. The "Yi Xinou" railway constructed by the "Belt and Road" strategy will help Zhejiang better move towards the Central Asian market, and will also provide great convenience for the cooperation areas along the route to achieve external linkages. Commercial and logistics parks should play the role of "overseas warehouses" for cross-border e-commerce, and deploy technology parks in major node cities.

\subsection{Layout overseas innovation centers with leading enterprises in the industry as the backbone}

Promote the transformation of technological innovation and achievements of Zhejiang Province with the provincial technological innovation benchmarking national technological innovation to lead the industrial development, and make it an important part of the construction of Zhejiang's technological innovation system. In view of the development stage of the enterprise, which determines the speed of the company's "going global" process to a large extent, and the depth and breadth of participation in international scientific and technological cooperation, it is recommended to focus on supporting 146 Zhejiang backbone enterprises, 3973 high-tech enterprises and listing Enterprises participate in international scientific and technological cooperation. In terms of support, concentrated resources are tilted towards key enterprises and industries. It will focus on supporting scientific and technological exchanges and cooperation between Zhejiang's 42 massive economies and 9 strategic emerging industries.

\subsection{Layout overseas innovation centers with the country leading in science and technology as the destination}

According to the industrial and technological development of the host country and the innovative ecological concept of the integration of the industrial chain and the innovation chain, adhere to high-end leadership and focus on key areas, such as information technology, high-end software and information services, biotechnology and new medicine, new materials, and high-end equipment Strategic emerging industries such as manufacturing, new energy and energy Internet, and digital creativity, accurately build an innovation chain with overseas technology parks as the carrier, and form an industrial innovation pattern of internal and external innovation and development. At present, Alibaba enterprises in Zhejiang Province are an advanced case in both innovation and development in the province and the country.

\subsection{Layout of overseas innovation centers based on the requirements of international standards}

It is a systematic project for enterprises to go out and carry out international scientific and technological cooperation. It is necessary to focus the resources of the provincial commerce, 
development and reform, science and technology, finance, taxation, financial affairs office, foreign expert bureau and other departments, and build a province-wide policy system to support enterprises to carry out international scientific and technological cooperation. In particular, we must strive to make breakthroughs in policy in response to outstanding issues such as financing, talents, and taxes encountered by enterprises. In terms of talent policy, it is necessary to increase the training of "going out" talents of Zhejiang enterprises, especially to support the exchange and learning of young and middle-aged talents of enterprises to overseas universities and scientific research institutions, and to improve the participation of high-level and substantial international cooperation and scientific and technological personnel of enterprises The ability to communicate. For the R \& D expenses incurred by an enterprise to establish an overseas R \& D institution, the overseas R \& D institution and the parent company are allowed to file a combined tax declaration, and the R \& D expenses are deducted before tax at $150 \%$.

\section{References}

[1] Etzkowitzh, Klofstenm. The innovating region: toward a theory of knowledge-based regional development. R \& D Management, 2005 (3): 243-255.

[2] Oksanenk, Hautamakia. Transforming regions into innovation ecosystems: a model for renewing local industrial structures. The Innovation Journal: The Public Sector Innovation Journal, 2014 (2): 2-16.

[3] Hu Yaohui. Research on the Industrial Technology Innovation Chain of the Science and Technology Park in the Industrial Transfer Demonstration Zone. Science \& Technology Progress and Policy, 2012 (14): 60-63.

[4] RATINHOT, HENRIQUES E. The role of science parks and business incubators in converging countries: evidence from Portugal. Technovation, 2010, 30 (4): 278-290.

[5] Liu Xinwei. Infrastructure is still the bottleneck of Africa's development. Building overseas parks together is the way out. China Foreign Trade, 2017 (11): 64-65. 